N.N. Zablodskii, V.E. Pliugin, A.N. Petrenko

\title{
USING OBJECT-ORIENTED DESIGN PRINCIPLES IN ELECTRIC MACHINES DEVELOPMENT
}

Purpose. To develop the theoretical basis of electrical machines object-oriented design, mathematical models and software to improve their design synthesis, analysis and optimization. Methodology. We have applied object-oriented design theory in electric machines optimal design and mathematical modelling of electromagnetic transients and electromagnetic field distribution. We have correlated the simulated results with the experimental data obtained by means of the double-stator screw dryer with an external solid rotor, brushless turbo-generator exciter and induction motor with squirrel cage rotor. Results. We have developed object-oriented design methodology, transient mathematical modelling and electromagnetic field equations templates for cylindrical electrical machines, improved and remade Cartesian product and genetic optimization algorithms. This allows to develop electrical machines classifications models, included not only structure development but also parallel synthesis of mathematical models and design software, to improve electric machines efficiency and technical performance. Originality. For the first time, we have applied a new way of design and modelling of electrical machines, which is based on the basic concepts of the objectoriented analysis. For the first time is suggested to use a single class template for structural and system organization of electrical machines, invariant to their specific variety. Practical value. We have manufactured screw dryer for coil dust drying and mixing based on the performed object-oriented theory. We have developed object-oriented software for design and optimization of induction motor with squirrel cage rotor of AIR series and brushless turbo-generator exciter. The experimental studies have confirmed the adequacy of the developed object-oriented design methodology. References 12, figures 2.

Key words: electric machine, object-oriented, class, object, template, inheritance, hierarchy, designing, mathematical modeling, electromagnetic field, optimization, algorithm.

Выполнен анализ применимости теории объектно-ориентированного анализа в проектировании и математическом моделировании электрических машин. Рассмотрены объектно-ориентированные модели электрических машин, синтез которых осуществляется как на основе положений теории электромагнитного поля, так и на основе дифференциальных уравнений электромагнитных переходных процессов. Обоснованы преимущества объектноориентированного подхода в проектировании. Определены основные принципы объектно-ориентированного проектирования. Библ. 12, рис. 2.

Ключевые слова: электрическая машина, объектно-ориентированный, класс, объект, шаблон, наследование, иерархия, проектирование, математическое моделирование, электромагнитное поле, оптимизация, алгоритм.

Introduction. Development and modernization of electric machines (EM) with high technical and economic performance is a priority for today's enterprises of electric machine industry $[1,2]$. The development of new versions of EM is realized by an individual approach to each project.

However, the existing design methods based on the sequential organization of design stage, do not allow to implement the tasks associated with the following:

1) there is no possibility of the automated transfer of all or part of the project to create a new, which has both common features with the base, and their own;

2) there is no mechanism of inclusion in your existing project data dependencies of other projects;

3 ) it is impossible to apply modern methods of optimization based on an object-oriented representation of data;

4) the cost of resources for the design at the traditional sequential approach significantly inferior to the objectoriented systems.

In this connection, an important task is to validate such a design technique that will not only reduce the time of design work, but also to improve the process of creating of the EM due to the transfer of design techniques from the pre-formed database to a new combination of the EM components.

In [3-6] principles, methodology and implementation of object-oriented design (OOD), mathematical modeling and optimization of EM have been described. In this paper, the principles of objectoriented analysis (OOA) are considered in the realization of an integrated project of EM from calculation to optimization.

The goal of the work is the solution of the problem increasing the technical and economic parameters of EM and shortening their development by using OOD.

Problem definition. Traditional design is accompanied by so-called «procedural» approach to solving the problems of the calculation of the electrical machine. The project, built on the basis of a procedural method is divided into calculated blocks, each of which performs a certain sequence of actions completed and has clearly expressed-linkages with other units of the project. Calculations are divided into successively performed points with a set of formulas rigidly interconnected by input and output data. A large number of links between 
the calculated blocks and data, in turn, gives rise to several problems: first, the complicated structure of the project; secondly, the project becomes difficult to make changes. The development costs of these projects are very high, which affects the additional material costs and higher cost of production. In this connection, such an organization of the EM design which would allow to increase the efficiency of the development of new projects, as well as modification of existing ones with minimal resource and time consuming, is of great importance in today's electrical machine industry.

Object-oriented design implements the concept of problem solving, using models based on the concepts of the real world. The fundamental elements are the class and object [7]. The classes allow to carry out the construction of individual components having simple tools. The object at the same time brings together a data structure (parameters with calculated procedures).

The underlying idea of the OOD is to join data and actions performed on that data, in a single unit, which is called an object. As an example, Fig. 1 shows the structure of the OOD to the DC motor.

Object-oriented project may be represented as «Electrical Designer» when from out-established blocks a new EM modification is assembled. Thus, Fig. 2 illustrates OOD of a screw motor with a massive rotor which is composed from modules of the induction motor (IM), machine with a massive rotor and screw.

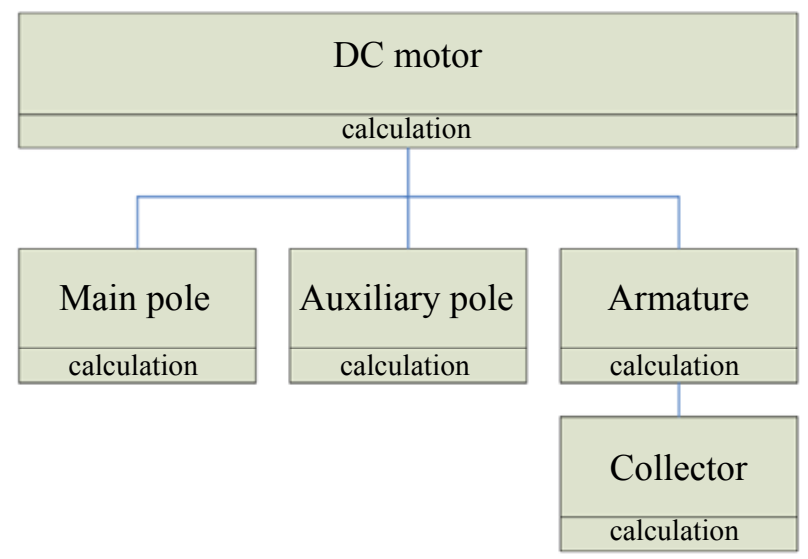

Fig. 1. Inheritance tree of DC motor in the OOD

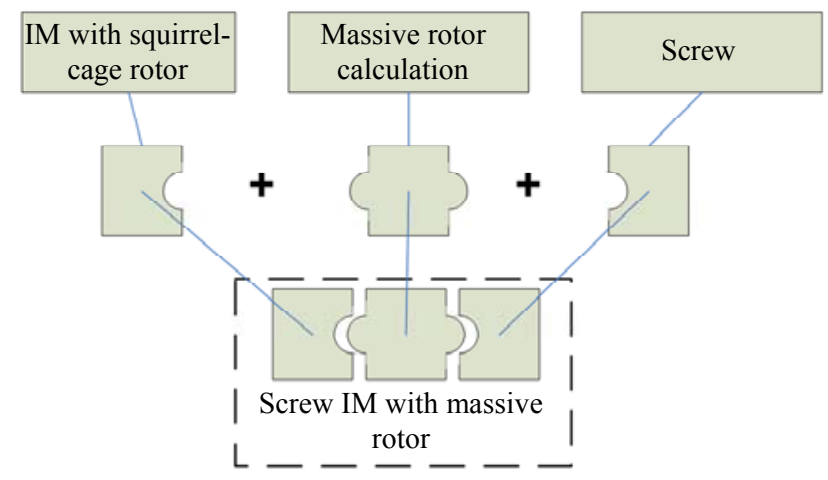

Fig. 2. Synthesis of the OO project of the screw IM with massive rotor
Creation of new projects at the OOD, as well as modification of existing ones is based on the experience of previous designs, resulting in a significant reduction in development time, reduces the probability of introducing errors into the new project.

Results of investigations. In OOD the project is represented as discrete objects, which contain the data and computational blocks with a set of formulas and logical connections [3, 7]. The characteristics and the basic principles of construction of the object in this case are: individuality; classification; inheritance; polymorphism.

Considering the theory of OOD, we go out from the point which assumes a basic class of generalized EM, descendants of which are well-known types of EM. By inheritance, using OOD principles discussed, added to or cut off those features which lead to the synthesis of a specific model of EM.

As the base, in terms of the OOD we accept Maxwell equations of classical electrodynamics [8]:

$$
\left\{\begin{array}{l}
\operatorname{rot} \vec{E}=-\frac{\partial \vec{B}}{\partial t}, \\
\operatorname{div} \vec{D}=\rho, \\
\operatorname{rot} \vec{H}=\vec{J}+\frac{\partial \vec{D}}{\partial t}, \\
\operatorname{div} \vec{B}=0
\end{array}\right.
$$

In (1) vectors of electric field strength $\vec{E}$ and magnetic field strength $\vec{H}$ are connected by the relations:

$$
\vec{D}=\varepsilon \varepsilon_{0} \vec{E}, \quad \vec{B}=\mu \mu_{0} \vec{H}, \quad \vec{J}=\sigma \vec{E},
$$

with vectors of electric $\vec{D}$ and magnetic $\vec{B}$ inductions, vector of the electric current density $\vec{J}$, which represent the medium response on the presents of the electromagnetic field in it. Respectively, $\rho$ is the volume density of the electric charge, $\varepsilon_{0}$ and $\mu_{0}$ are electric and magnetic constants, $\sigma$ is the conductivity, $\varepsilon$ and $\mu$ are dielectric and magnetic permeabilities of the medium.

An analysis of the work performed shows that Maxwell equations (1), (2), which are fundamental to the theory of EM, fully confirm the stated principles of the OOD, thus proving the viability of the object-oriented approach in the design of EM. Thus, the development of theoretical bases of the OOD, in addition, that it improves the efficiency and quality of design does not contradict the principles of formation of electromagnetic structures in EM.

Practical implementation of the OOD has been made in the programming language Java [6]. In the project were implemented stages of the design, including electromagnetic calculation as well as thermal, reliability, economic.

Used object-oriented optimization algorithms, such as the Cartesian product of the sets (CPS) and genetic algorithm (GA), make it possible to perform calculations of the machine with all possible combinations of variable variables within specified limits and at a predetermined 
step while changing simultaneously the variable parameters $[9,10]$.

To improve the efficiency of the algorithm of the CPS sampling procedure combinations authenticated the restrictions it has been modified by the authors that the increased performance of the algorithm is more than in 10 times [11].

Genetic optimization algorithm in the classical formulation was modified and practically realized by the authors for the EM data sample, and adding changes in the range of varied variables without invasion into the internal structure of the algorithm [12].

After the completion of the last phase of optimization automated parametric design of optimal motor in AutoCAD or COMPAS with automatic generation of design and drawing documentation is performed [6].

OOP principles allow not only synthesize the EM design techniques, but also consider their mathematical models of hereditary succession of the base class and descendant classes. This will go to the designing as a complex task, decisive problems of obtaining the parameters and characteristics of EM in steady-state and transient modes. Here, automated generation of mathematical model of a random kind of EM at the design stage is performed.

The system of equations of the EM of basic machine describes the energy conversion process and consists of four Kirchhoff equations, equations of the electromagnetic torque and movement. Based on the analysis mathematic models of different types of EM, a table of modifications, allowing to generate their model using OOD principles is built. Synthesis of models of EM was accompanied by the formation of the table of modifiers, which are the coefficients or terms, changing the matrix of basic parameters of the mathematical model [3].

Using a template class of generalized EM and selecting certain features, you can go to the object of particular EM [4]. A mathematical model of transient processes in at the OOD is formed on the base of the hierarchical tree of inheritance, modifiers tables compiled for the designed machine.

Practical implementation of the OOD of the EM is confirmed by the utilization at industrial enterprises of Ukraine.

The screw induction motor (SIM), manufactured by JSC «Pervomaisky Electromechanical Plant named after K. Marx» was developed and implemented in the production process of mixing and drying of coal sludge at JSC «Central Concentration Plant Selidovskaya».

For the SIM, the object-oriented design methodology was compiled, it was practically implemented in the programming language Java, objectoriented mathematical simulation of electromagnetic transients and the analysis of the distribution of the electromagnetic field were performed.

Using the principles of OOP techniques and a computer program in Java language for the optimal design and the study of transient modes of an induction motor for electric rolling stock have been developed. The results of calculations were the basis of field calculations in 2D and $3 \mathrm{D}$ formulations to improve the thermal performance of the motor.

As an object of design was also considered a multiphase brushless synchronous exciter БTB-12(15) (State Plant «Electrotyazhmash», Kharkiv) designed for systems of the brushless excitation of the turbine generator (BETG) of $80 \mathrm{MW}$. Object-oriented class structure of the BETG project was implemented in the form of software in Java.

As an object of design an asynchronous motor with a squirrel-cage rotor of АИР series was considered, developed at the company Special Design Bureau «Ukrelectromach». In the course of the work done objectoriented design was done, a computer program in Java was created, multi-criteria optimization of the IM using the CPS algorithm was made. As a result of optimization parameters of the IM with squirrel-cage rotor were obtained having improved in the comparison to the base case, the technical and economic performance.

Thus, the technique of the OOD of the EM was practically implemented in the projects that have received practical application in industry.

\section{Conclusions.}

1. Object-oriented design has allowed to realize the formation of project methods and mathematical models of EM by using information of base classes of the project using modifiers and operators of synthesis. Unified template allows to transfer elaborated project data to new versions of EM.

2. Object-oriented methodology of mathematical modeling of EM allows the synthesis of mathematical models of the existing types of EM, and to predict the possible modification of new structures.

3. The use of OOD principles leads to a significant reduction in terms of the design, along with opportunities to perform engineering design optimization, mathematical modeling of electromagnetic transients and the analysis of the distribution of the electromagnetic field of EM in the frame one project.

4. The use of object-oriented methods of optimization is allowed to raise such technical and economic performance of EM such as efficiency, cost, power factor, improve the performance of starting and operating characteristics.

\section{REFERENCES}

1. Expediting and validating development. Available at: http://www.iff.fraunhofer.de/en (accessed 12 September 2015).

2. R-Designed. Available at: http://blog.caranddriver.com/rdesigned-2016-volvo-xc90-gets-the-sporty-r-design-treatmentstill-isnt-on-sale-yet/ (accessed 12 September 2015). 
3. Pliugin V.E. Teoreticheskie osnovy ob'ektnoorientirovannogo rascheta $i$ proektirovaniia elektromekhanicheskikh ustroistv [Theoretical basis of electromechanical devices object-oriented calculation and design]. Alchevsk, Lado Publ., 2014. 200 p. (Rus).

4. Pliugin V., Milykh V., Polivianchuk A., Zablodskiy N. Using of object-oriented design principles in mathematic modeling of electric machines. MOTROL - Motoryzacja i Energetyka Rolnictwa, 2015, vol.15, no.2, pp. 25-32.

5. Pliugin V., Shilkova L., Letl J., Buhr K. Analysis of the electromagnetic field of electric machines based on objectoriented design principles. Proceedings $36^{\text {th }}$ PIERS. Prague: Electromagnetic Academy, 2015, pp. 2522-2527.

6. Zablodskii M.M., Pliugin V.E., Buhr K. SAPR elektromekhanichnykh prystroiv. - Navchalnyi posibnyk. Ch.2 [CAD of electromechanical devices. - Textbook. Vol.2]. Alchevsk, Lado Publ., 2013. 320 p. (Ukr).

7. Buch G. Ob'ektno-orientirovannyj analiz i proektirovanie [Object-oriented analysis and design]. Moscow, Binom Publ., 1998. 560 p. (Rus).

8. Beljaev E.F., Shulakov N.V. Diskretno-polevye modeli elektricheskih mashin [Discrete field models of electrical machines]. Perm, Perm State Technical University Publ., 2009. 457 p. (Rus).

9. Vereshhagin N.K., Shen' A. Lekcii po matematicheskoj logike i teorii algoritmov. Nachala teorii mnozhestv [Lectures on mathematical logic and theory of algorithms. Beginning of set theory]. Moscow, MCNMO Publ., 2008. 198 p. (Rus).
10. Emel'janov V.V., Kurejchik V.V., Kurejchik V.M. Teorija i praktika evoljucionnogo modelirovanija [Theory and practice of evolutionary modeling]. Moscow, Phizmatlit Publ., 2003. 432 p. (Rus).

11. Zablodskiy N., Pliugin V., Lettl J., Buhr K., Khomitskiy S. Induction motor optimal design by use of cartesian product. Transactions on electrical engineering, 2013, no.2, pp. 54-58.

12. Zablodskiy N., Pliugin V., Lettl J., Buhr K., Khomitskiy S. Induction motor design by use of genetic optimization algorithms. Transactions on electrical engineering, 2013, no.3, pp. 65-69.

Received 22.10.2015

N.N. Zablodskii ${ }^{1}$, Doctor of Technical Science, Professor, V.E. Pliugin ${ }^{2}$, Candidate of Technical Science, Associate Professor,

A.N. Petrenko ${ }^{3}$, Candidate of Technical Science, Associate Professor,

${ }^{1}$ National University of Life and Environmental Sciences of Ukraine,

15, Heroyiv Oborony Str., Kyiv, 03041, Ukraine.

phone +38 044 5278242, e-mail: zablodskiynn@gmail.com

${ }^{2}$ National Technical University «Kharkiv Polytechnic Institute», 21, Frunze Str., Kharkiv, 61002, Ukraine.

phone +38 057 7076600, e-mail: vlad.plyugin@gmail.com

${ }^{3}$ O.M. Beketov National University of Urban Economy in Kharkiv,

17, Marshal Bazhanov Str., Kharkiv, 61002, Ukraine. phone+38057 7061548, e-mail: petersanya2007@mail.ru

How to cite this article:

Zablodskii N.N., Pliugin V.E., Petrenko A.N. Using object-oriented design principles in electric machines development. Electrical engineering \& electromechanics, 2016, no.1, pp. 17-20. doi: 10.20998/2074-272X.2016.1.03. 